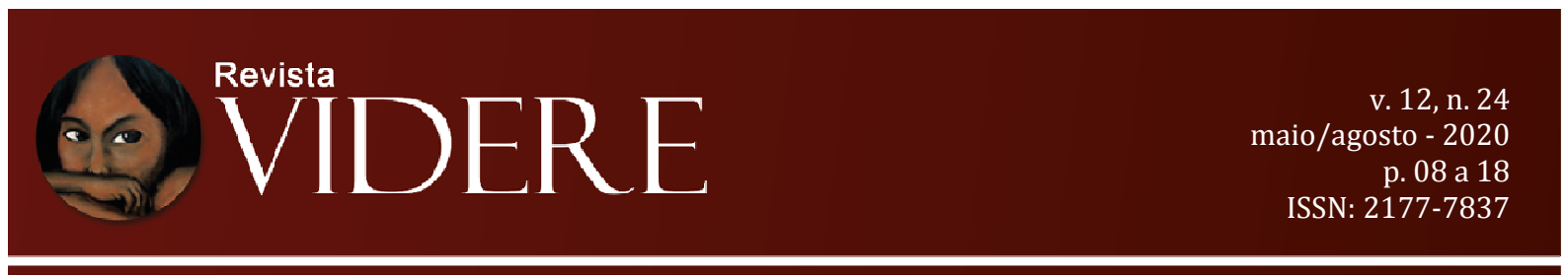

\title{
A VIOLAÇÃO DE DIREITOS DA PERSONALIDADE DO AUTOR PELA PRÁTICA DO GHOST WRITER
}

\author{
THE VIOLATION OF THE PERSONALITY RIGHTS OF THE AUTHOR BY \\ THE PRACTICE OF GHOST WRITER
}

\author{
Leonardo Estevam de Assis Zanini \\ Livre-docente e Doutor em Direito Civil (USP), Brasil \\ E-mail: assiszanini@gmail.com \\ OrcID: 0000-0002-9057-4387
}

\begin{abstract}
RESUMO: O presente artigo realiza um breve estudo sobre o regime jurídico do direito ao reconhecimento da autoria e a figura do ghost writer no direito brasileiro. Para tanto, faz uso das decisões judiciais proferidas no caso Bruna Surfistinha, as quais discutiram a autoria da obra literária "O Doce Veneno do Escorpião", que relata a vida da personagem Bruna Surfistinha. Trata-se de pesquisa que utiliza metodologia descritiva, baseada fundamentalmente na investigação bibliográfica, o que é feito para analisar a solução judicial dada ao caso objeto do estudo. Os temas mais relevantes da matéria são debatidos, como o direito ao reconhecimento da autoria, a obra protegida pelo direito de autor, bem como as convenções envolvendo a figura do ghost writer. Merece ainda destaque a apresentação de breves notas acerca do problema do ghost writer na Alemanha e na França. Assim sendo, o objetivo desse trabalho é discutir se a solução judicial dada ao caso Bruna Surfistinha foi a mais adequada, considerando o direito de autor, o direito ao reconhecimento da autoria e as convenções de ghost writer.
\end{abstract}

PALAVRAS-CHAVE: direitos da personalidade; direito de autor; direito moral de autor; direito ao reconhecimento da autoria; ghost writer.

ABSTRACT: The present article makes a brief study on the legal regime of the right to recognition of authorship and the figure of the ghost writer in Brazilian law. In order to do so, it makes use of the judicial decisions rendered in the Bruna Surfistinha case, which discussed the authorship of the literary work "O Doce Veneno do Escorpião" (The Sweet Poison of the Scorpion), which reports on the life of the character Bruna Surfistinha. It is a research that uses descriptive methodology, based fundamentally on bibliographic research, which is done to analyze the judicial solution given to the case object of the study. The most relevant issues of the matter are analyzed, such as the right to recognition of authorship, the work protected by the copyright law, as well as the conventions involving the figure of the ghost writer. It is also worth mentioning the presentation of brief notes on the problem of the ghost writer in Germany and France. Therefore, the objective of this work is to discuss if the judicial solution 
given to the Bruna Surfistinha case was the most adequate, considering the copyright, the right to the recognition of authorship and the ghost writer conventions.

KEYWORDS: rights of the personality; copyright; right to recognition of authorship; ghost writer.

\section{Introdução}

No ano de 2005 foi lançado no Brasil o livro “O Doce Veneno do Escorpião: O diário de uma garota de programa", que rapidamente se tornou bastante conhecido, vendendo milhares de cópias. A obra, que foi inclusive publicado em muitos outros países, relata a história de Raquel Pacheco, conhecida como Bruna Surfistinha, uma jovem da classe média da cidade de São Paulo que resolveu abandonar a sua família para se tornar uma garota de programa.

Em face do grande sucesso do livro, as aventuras sexuais e afetivas da garota de programa foram transportadas para as telas de cinema, com o lançamento, no ano de 2011, do filme "Bruna Surfistinha", dirigido por Marcus Baldini. Entretanto, o best-seller que deu origem ao filme não foi redigido pela própria personagem, mas sim por um escritor contratado para a sua elaboração, não obstante constar Bruna Surfistinha como sendo a sua autora.

Dessa maneira, após o sucesso de vendas no Brasil e no exterior, o verdadeiro escritor, Jorge Roberto Tarquini, ajuizou ação contra Raquel Pacheco e a Editora Original, responsável pela publicação do livro, alegando que o livro não tinha sido escrito pela personagem, mas sim pelo autor da ação. Pediu-se na demanda o reconhecimento de Tarquini como o único autor do livro, bem como o pagamento de indenização pela violação dos direitos patrimoniais e morais do escritor.

Diante desse quadro, o presente artigo se propõe a analisar o problema jurídico resultante da atuação do ghost writer, levando em conta as decisões judiciais proferidas no caso Bruna Surfistinha, bem como a adequação dos julgados à legislação e às construções doutrinárias. Para tanto, antes da discussão acerca dos problemas jurídicos apresentados pelo ghost writer, é necessária a compreensão do direito moral do autor ao reconhecimento da autoria.

\section{$2 \mathrm{O}$ direito ao reconhecimento da autoria}


O criador de uma obra usualmente quer ser reconhecido como seu autor, pois a assinatura de um trabalho pode influir positivamente na forma como ele é visto pela sociedade. Logicamente, a boa fama, eventualmente adquirida pelo autor, está diretamente ligada à qualidade da manifestação de sua personalidade inserida na própria obra.

A assinatura de um trabalho é, sem dúvida, uma forma de se fazer conhecido em seu tempo. Também permite a imortalização da personalidade, que se torna presente também na posteridade, visto que o autor continua vivo em sua obra (SCHACK, 2010, p. 184).

Com efeito, mesmo antes do surgimento da legislação protetiva, a ligação da obra ao nome do autor já tinha a função de garantir a defesa contra falsários, que encontravam maiores dificuldades para lesar o autor de uma obra assinada. Michelangelo, por exemplo, procedeu desse modo ao completar sua obra Pietá, no ano de 1501, uma vez que prontamente assinou seu nome (SCHACK, 2010, p. 184).

Pois bem, na medida em que a proteção do autor foi evoluindo, percebeu-se que o reconhecimento da autoria, também conhecido como direito de paternidade do autor, consistia no ponto mais fundamental e menos contestado dessa tutela, visto que diretamente ligado ao direito geral da personalidade (STROWEL, 1993, p. 496).

O direito ao reconhecimento da autoria é, então, no quadro dos direitos da personalidade do autor, o tema central de proteção (DIETZ; PEUKERT, 2010, p. 871). Tanto é assim que, conforme ensina Chinellato, "não se encontrou nenhuma legislação que não o reconheça, pois é considerado um dos primeiros e mais importantes direitos morais do autor" (CHINELLATO, 2008, p. 166) ${ }^{1}$.

Nesse contexto, o direito ao reconhecimento da autoria protege a vinculação personalística existente entre o autor e a obra ${ }^{2}$. Encontra previsão expressa na Lei 9.610/98 (legislação sobre direitos autorais), a qual estabelece que o autor tem o direito moral de reivindicar, a qualquer tempo, a autoria da obra, bem como de ter seu nome, pseudônimo ou sinal convencional indicado ou anunciado, como sendo o do autor, na utilização da obra (art.

\footnotetext{
${ }^{1}$ No que diz respeito aos países que adotam o sistema do copyright, é certo que a legislação normalmente não contém normas gerais sobre o reconhecimento da paternidade. No entanto, mesmo nesses ordenamentos avessos aos direitos da personalidade do autor, há disposições que permitem inferir a existência do direito ao reconhecimento da autoria, como é o caso da obrigação de indicar a fonte (LIPSZYC, 1993, p. 166).

${ }^{2}$ Conforme ensina Pontes de Miranda, essa "identificação pessoal, essa ligação do agente à obra, essa relação de autoria, é o vínculo psíquico, fático, inabluível, portanto indissolúvel" (PONTES DE MIRANDA, 2000, p. 177). De acordo com Adriano de Cupis, a "paternidade intelectual representa um vínculo espiritual indissolúvel entre o autor e a sua obra" (CUPIS, 2004, p. 336).
} 
24, I e II $)^{3}$. Ademais, o art. 12 da mesma lei prevê ainda que o autor de obra literária, artística ou científica, para se identificar como tal, poderá "usar de seu nome civil, completo ou abreviado até por suas iniciais, de pseudônimo ou qualquer outro sinal convencional" ${ }^{4}$. Por fim, faz-se necessário lembrar que o autor é considerado pela lei como a pessoa física criadora de obra literária, artística ou científica (art. 11 da Lei 9.610/98) ${ }^{5}$.

\section{A argumentação utilizada nas decisões judiciais do caso Bruna Surfistinha}

Feitas as observações anteriores de ordem teórica, é certo que na jurisprudência brasileira não é muito comum o exame e a apresentação de discussões voltadas especificamente para o tema do direito de paternidade sobre uma obra. Apesar disso, no caso Bruna Surfistinha os problemas do direito de paternidade e do ghost writer foram o objeto precípuo da discussão, o que justifica a presente análise.

Pois bem, a demanda foi proposta pelo escritor Jorge Roberto Tarquini, que pretendia ver reconhecido o seu direito à paternidade exclusiva sobre a obra "O doce veneno do escorpião", não obstante ter celebrado com a editora corré (Editora Original) um contrato de cessão de direitos autorais. Argumentou o autor que para a criação do livro foram necessárias pesquisas de campo e entrevistas com a corré Raquel. Além disso, ressaltou que o ineditismo do trabalho está na seleção do material e no fato de terem sido intercaladas as histórias vividas por "Bruna Surfistinha" e por "Raquel", o que revela ao leitor o motivo que levou a protagonista a fugir de casa e se transformar em uma garota de programa.

Em primeira instância foi decidido que a parte autora não criou nenhuma obra. $\mathrm{O}$ magistrado asseverou que a simples tarefa de redigir os acontecimentos vivenciados pela corré Raquel e pela personagem por ela inventada não podia ser qualificada como qualquer tipo de produção literária, artística ou criativa. A sentença então qualificou a atividade do escritor como a de um mero prestador de serviços, julgando improcedente o pedido.

Em sede de apelação, o Tribunal de Justiça de São Paulo ponderou que a editora corré contratou os serviços do escritor para, na condição de ghost writer, organizar os fatos e as

\footnotetext{
${ }^{3}$ Art. 24 da Lei 9.610/98: "São direitos morais do autor: I - o de reivindicar, a qualquer tempo, a autoria da obra; II - o de ter seu nome, pseudônimo ou sinal convencional indicado ou anunciado, como sendo o do autor, na utilização de sua obra;".

4 Art. 12 da Lei 9.610/98: "Para se identificar como autor, poderá o criador da obra literária, artística ou científica usar de seu nome civil, completo ou abreviado até por suas iniciais, de pseudônimo ou qualquer outro sinal convencional".

5 Art. 11 da Lei 9.610/98: “Autor é a pessoa física criadora de obra literária, artística ou científica". \begin{tabular}{l|l} 
Revista Videre, Dourados, v. 12, n. 24, maio/ago., 2020 - ISSN: 2177-7837 & do https://doi.org/10.30612/videre.v12i24.9953
\end{tabular}
} 
histórias contadas pela corré Raquel e, a partir daí, redigir o livro que foi publicado. Aliás, o voto do relator evidenciou em que consistiu o trabalho da parte autora no seguinte trecho:

O recorrente, por sua vez, com a sua grande habilidade profissional, pôde transformar todo o referido conteúdo recebido em um sucesso editorial, mas justamente prestando o serviço de transportar para a forma escrita as palavras e sentimentos emitidos pela recorrida Raquel, bem como, posteriormente, escolhendo as histórias e as ordenando de forma a trazer um conteúdo de mistério e envolvimento ao leitor, captando o espírito do próprio gênero literário e desenvolvendo com eficiência o próprio trabalho para o qual foi contratado ${ }^{6}$.

O acórdão do Tribunal de Justiça de São Paulo ainda declarou que o autor tinha ciência, ao assinar o contrato, de que não seria considerado o criador da obra. Por isso, o sodalício entendeu serem aplicáveis ao caso os princípios da boa-fé objetiva, do consensualismo e da autonomia da vontade, uma vez que os contratantes, de livre e espontânea vontade, pontuaram como a relação jurídica se desenvolveria (TJSP, 2011, online).

Vale notar que no Superior Tribunal de Justiça o julgado do Tribunal de Justiça de São Paulo foi mantido, mas a decisão não ingressou no mérito, afastando o recurso ao argumento de que a simples pretensão de reexame de provas não enseja Recurso Especial ${ }^{7}$.

Por conseguinte, reconheceu-se a validade do negócio jurídico de cessão dos direitos autorais, bem como a ausência de violação a direitos morais e patrimoniais, pelo que a obra teria sido corretamente atribuída unicamente à corré Raquel ${ }^{8}$.

\footnotetext{
${ }^{6}$ Transcrevemos a ementa do julgado: "RESPONSABILIDADE CIVIL. DIREITO AUTORAL. PEDIDO DE RECONHECIMENTO DO 'GHOST WRITER' (ESCRITOR FANTASMA) COMO ÚNICO E EXCLUSIVO AUTOR DA OBRA LITERÁRIA 'O DOCE VENENO DO ESCORPIÃO'. OBRIGAÇÃO DE FAZER. RESSARCIMENTO POR DANOS PATRIMONIAIS E MORAIS. IMPOSSIBILIDADE POR AUSÊNCIA DE CRIAÇÃO E FALTA DE PREVISÃO LEGAL. ANÁLISE DO CONTRATO FIRMANDO ENTRE APELANTE E A APELADA EDITORA. PRELIMINARES DE NULIDADE. REJEITADAS. SENTENÇA MANTIDA. RECURSO IMPROVIDO" (TJSP, 2011, on-line).

7 Transcrevemos a ementa do julgado: "RECURSO ESPECIAL. DIREITO AUTORAL. RESPONSABILIDADE CIVIL. CESSÃO DE DIREITOS. LIVRO "DOCE VENENO DO ESCORPIÃO". 1 Pedido de reconhecimento do "ghost writer" como único e exclusivo autor da obra-literária denominada "Doce Veneno do Escorpião". 2 - O reconhecimento da ocorrência de cerceamento de defesa exigiria a revisão do contexto fático probatório. Súmula 07/STJ. 3 - A alteração das conclusões a que chegaram as instâncias de origem acerca da atuação do demandante na realização da obra autobiográfica da sua autora, conhecida pelo pseudônimo de "Bruna Surfistinha", não dispensaria a revisão do conteúdo do contrato celebrado e das provas coletadas. Incidência das súmulas 05 e 07/STJ. 4 - Dúvida relativa à correção dos pagamentos efetuados deve ser veiculada mediante ação de prestação de contas. 5 - RECURSO ESPECIAL DESPROVIDO” (STJ, 2015, online).

${ }^{8}$ Em outros julgados, também tratando de ghost writer em obras biográficas, pode-se notar a adoção do mesmo entendimento seguido no caso Bruna Surfistinha: "DIREITO AUTORAL. OBRA AUTOBIOGRÁFICA. GHOST-WRITER. ESCRITOR FANTASMA. AUSÊNCIA DE CRIAÇÃO. O escritor contratado para redigir biografia com base nas narrativas do contratante, não produz obra amparada pelo direito autoral, estando correto o indeferimento do seu pedido para que dela conste como coautor". (TJMG, 2016, on-line).
} 


\section{A obra protegida pelo direito de autor}

No caso em questão, não resta dúvida que se está diante de um contrato de ghost writer, onde o autor da ação judicial realizou pesquisas e entrevistas e, a partir daí, fazendo uso de seu espírito criativo, construiu a obra "O doce veneno do escorpião".

Nessa linha, é fundamental a análise do problema relacionado à obra protegida pelo direito de autor, pois, antes mesmo da discussão acerca do contrato de ghost writer, é mister se saber se o autor da ação judicial realmente produziu uma obra protegida pelo direito de autor.

O art. $7^{\circ}$ da Lei 9.610/98 estabelece que são "obras intelectuais protegidas as criações do espírito, expressas por qualquer meio ou fixadas em qualquer suporte, tangível ou intangível, conhecido ou que se invente no futuro". Assim sendo, é certo que coube ao escritor, autor da ação judicial, a criação do livro, pois foi ele quem selecionou as situações que reputou mais coerentes e interessantes, criou uma narrativa que intercalou fatos ocorridos antes e depois da fuga de Raquel de sua casa, bem como imprimiu na obra a sua personalidade, em particular a sua forma de ver a vida e as experiências das personagens abordadas.

Ora, a lei autoral, como mencionada, somente dá proteção às criações do espírito que foram expressas ou fixadas em um suporte, seja ele tangível ou não, sendo irrelevante se os fatos foram anteriormente narrados pela protagonista da obra. Se não fosse esta a correta interpretação a ser dada à lei, toda e qualquer obra biográfica não poderia ser imputada a outra pessoa que não fosse aquela da qual a criação conta a história de vida.

Realmente, não se poderia pensar, por exemplo, na biografia de uma pessoa famosa que não fosse por ela mesma escrita, uma vez que no processo de elaboração desse tipo de trabalho também são feitas pesquisas e entrevistas com os personagens envolvidos. Igualmente, seria inadmissível uma biografia póstuma, ou seria necessário atribuir a biografia póstuma à própria pessoa já falecida.

Desse modo, ainda que a colheita do material para a criação do livro tenha vindo em grande parte dos relatos da corré Raquel, coube ao escritor todo o trabalho de produção da obra, incluindo aí a ideia de intercalar momentos diferentes da vida da protagonista, o que certamente encontra proteção na lei autoral brasileira, conforme dispõe o art. $7^{\circ}$ da Lei 9.610/98. Ademais, deve-se ainda notar que a proteção à obra intelectual abrange o seu título, 
se original e inconfundível com o de obra do mesmo gênero (art. 10 da Lei 9.610/98), mais um argumento que reforçaria a tese do autor da ação, haja vista que o título dado à obra, "O doce veneno do escorpião: O diário de uma garota de programa", preenche os requisitos mencionados 9 .

\section{As convenções sobre o direito de paternidade e a figura do ghost writer}

\subsection{Considerações iniciais}

As convenções envolvendo o direito ao reconhecimento da autoria são um assunto que tem causado muito desconforto entre os estudiosos. Elas são muito frequentes no âmbito da edição literária, mas também estão presentes no campo do audiovisual (VIVANT; BRUGUIÈRE, 2009, p. 312). No caso em questão, não há dúvida acerca da existência de uma convenção na qual o escritor contratado pela editora alienou o texto elaborado a Raquel Pacheco, que ficou conhecida pelo público como a autora do referido livro.

Esse tipo de problema não é nenhuma novidade, já existia antes mesmo do surgimento do direito de autor. De fato, na Antiguidade Clássica as convenções sobre o direito de paternidade já eram objeto de disputas. Muito comuns eram os casos em que um autor se despojava completamente do seu direito de paternidade sobre a obra, transferindo-o a outra pessoa, como se a autoria fosse meramente um direito de propriedade (ZANINI, 2015, passim).

Com o aperfeiçoamento da matéria, particularmente com o desenvolvimento dos direitos da personalidade, o problema passou a ser levado aos tribunais, onde os magistrados se viam diante de um dilema. Por um lado, o autor tem o direito de se manter anônimo, o que vincula aqueles que adquirem o direito de utilização da obra. Mas por outro lado, o autor não perde o direito ao reconhecimento da autoria (também chamado de direito de paternidade), ainda que tenha renunciado expressamente. E vale ressaltar que mesmo a ideia de anonimato é provisória, pois o autor pode se revelar a qualquer tempo ao público (GAUTIER, 2010, p. 237).

\footnotetext{
${ }^{9}$ Nessa situação também não se pode admitir que um simples agradecimento, feito no interior do livro, seja suficiente para afastar a paternidade do verdadeiro autor em relação à obra (GAUTIER, 2010, p. 236). 
Assim sendo, a validade das cessões do direito de paternidade por meio dos contratos conhecidos como de nègre (em francês) ${ }^{10}$ ou ghost writer (em inglês), nos quais um autor aceita a atribuição da paternidade de seu trabalho a outra pessoa (autor aparente), é matéria bastante discutível, trazendo principalmente à tona o problema da renúncia aos direitos da personalidade do autor (art. 27 de Lei 9.610/98) ${ }^{11}$.

5.2 Os primeiros passos da doutrina e da jurisprudência

Uma das primeiras demandas sobre a matéria envolveu os escritores Alexandre Dumas e Auguste Maquet e foi levada à Corte de Paris, onde se decidiu que o nome do autor poderia ser objeto de todo tipo de estipulação, admitindo-se inclusive sua omissão no título, desde que assim tivesse sido convencionado (LUCAS-SCHLOETTER, 2002, p. 456-457).

A admissão de cláusulas abdicativas ao direito de paternidade também pode ser encontrada em outras decisões francesas, mesmo após a Lei de 1957. Isso ocorreu, por exemplo, em uma ação em que se pretendia o reconhecimento do direito de Julia Daudet, esposa de Alphonse Daudet, de figurar como coautora dos livros de seu marido. No julgado foi evidenciado que a vontade comum do casal levou à publicação das obras em nome apenas de Alphonse Daudet (LUCAS; LUCAS, 2006, p. 371).

$\mathrm{Na}$ doutrina, uma das primeiras tentativas de solucionar o impasse foi apresentada em 1935, por Michaélidès-Nouaros, o qual entendia que deveriam ser declarados nulos os contratos em que ambas as partes tinham a intenção de enganar o público com a indicação de uma pessoa que não era o verdadeiro autor da obra. Em contrapartida, ainda com fundamento nos bons costumes e no interesse da coletividade, o estudioso advertia que deveriam ser tidos como válidos os contratos onde não restasse evidente a intenção de enganar o público (LUCAS-SCHLOETTER, 2002, p. 457).

A concepção, entretanto, peca justamente no ponto em que leva em consideração o interesse público como critério balizador da validade dos contratos de ghost writer. É que o eventual interesse da coletividade não passa de um elemento externo à contratação, que não guarda nenhuma relação com o direito de autor, cujo objetivo não é a proteção de produtos comerciais, nem a regulamentação da concorrência desleal e muito menos a tutela dos direitos

\footnotetext{
${ }^{10}$ A expressão francesa "conventions de négres", bastante deselegante, remete à ideia da exploração escravagista (VIVANT; BRUGUIÈRE, 2009, p. 312).

${ }^{11}$ Art. 27 da Lei 9.610/98: "Os direitos morais do autor são inalienáveis e irrenunciáveis". 
do consumidor, mas sim a proteção da personalidade do criador (LUCAS-SCHLOETTER, 2002, p. 457-458).

Dessa forma, por se tratar de um critério que nada tem a ver com o direito de autor, a ideia de se invalidar os contratos de ghost writer com base no interesse da coletividade foi abandonada. Por conseguinte, na linha do direito francês, não há espaço para a admissão da referida concepção no ordenamento jurídico brasileiro, visto que o sistema pátrio fundamenta a solução desse problema nos direitos da personalidade do autor (também conhecidos como direitos morais do autor), conforme será visto a seguir.

\section{$6 \mathrm{O}$ direito de paternidade e o ghost writer no caso Bruna Surfistinha}

Superada a discussão acerca da existência de uma obra protegida pelo direito de autor, passa-se propriamente ao problema da convenção de ghost writer.

Seguindo o entendimento dominante na Alemanha e na França, fica claro que é possível o não exercício do direito de paternidade por parte do autor, o que guarda paralelo com o direito ao anonimato. Nessa senda, como é admissível o não exercício do direito de paternidade por meio do anonimato, não haveria, em princípio, nenhum impedimento a que o autor deixasse de manifestar sua autoria e permitisse que outrem a assumisse (ZANINI, 2015, passim).

A situação não pode ser comparada com a renúncia ao direito de paternidade, vedada pela lei (art. 27 da Lei 9.610/98), visto que o que se está defendendo é simplesmente o seu não exercício (DIETZ, 2009, p. 98). Assim, admitindo-se o não exercício do direito de paternidade, que é um direito da personalidade do autor, nada impediria a celebração do negócio jurídico com o ghost writer, o qual seria considerado válido.

Entretanto, como o autor não pode renunciar ao direito de paternidade, cabendo-lhe o direito de reivindicá-lo a qualquer tempo, independentemente dos direitos patrimoniais e mesmo depois de sua cessão ${ }^{12}$, é certo que eventual contratação envolvendo o direito de paternidade tem caráter precário ou provisório (GAUTIER, 2010, p. 236).

Em realidade, o que ocorre é uma contratação onde o verdadeiro criador permite que terceiro seja tido temporariamente como autor (aparente), surgindo aí meramente uma

\footnotetext{
${ }^{12}$ No Brasil, vale aqui mencionar que Walter Moraes já cuidava do tema desde 1977, lecionando que "autor não pode negociar a autoria, não pode ceder a outrem a qualidade de autor. Um negócio desses, embora aconteça na prática, é de valor nenhum. E nesse caso, o autor pode, em qualquer tempo, voltar a exigir a indicação de seu nome ao pé da obra. A ação judicial que viesse a pleitear a reposição do nome seria causa seguramente ganha" (MORAES, 1977, p. 46). 
obrigação de não fazer (obligatio ad non faciendum), consistente em não reivindicar a paternidade da obra por um determinado lapso de tempo, que, por segurança, para que se evite discussões posteriores, deve ser expressamente prevista no contrato.

Desta feita, com a expressa previsão contratual, que obviamente não pode significar renúncia à paternidade, deve o verdadeiro autor se omitir no que toca à reivindicação da autoria por determinado período. Decorrido o prazo, é possível a reivindicação da paternidade, não cabendo ao outro contratante o direito ao pagamento de perdas e danos, visto que houve respeito à boa-fé e aos prazos estabelecidos contratualmente (ZANINI, 2015, passim).

Outrossim, no que toca à precariedade da contratação, acredita-se que é cabível no direito brasileiro, tal qual foi proposto por Osenberg no direito alemão, a limitação ao prazo máximo de cinco anos (OSENBERG, 1985, p. 119-120). Não seria então possível a pretensão de silêncio do verdadeiro autor quanto à paternidade da obra por prazo superior a cinco anos, findo o qual seria possível o reconhecimento da autoria sem nenhuma consequência obrigacional negativa para o verdadeiro criador da obra.

Ademais, o prazo de cinco anos decorre do próprio espírito da lei autoral brasileira, que não permite a cessão de direitos de autor sobre obras futuras por prazo superior a cinco anos (art. 51 da Lei 9.610/98) ${ }^{13}$ nem a transferência a terceiros dos direitos patrimoniais, quando não houver estipulação contratual escrita, por prazo superior a cinco anos (art. 49, III da Lei 9.610/98) ${ }^{14}$.

Assim sendo, se nestas hipóteses não é possível a cessão por prazo superior a cinco anos, também não se poderá pretender, por analogia, que a contratação de obrigação de não fazer, consistente em não reclamar a autoria e permitir que ela seja atribuída a outra pessoa, possa superar o prazo de cinco anos. Aliás, entendimento contrário poderia significar a própria renúncia ao direito de paternidade, o que não é admissível, visto que o direito ao reconhecimento da autoria faz parte do núcleo irrenunciável dos direitos da personalidade do autor (LETTL, 2008, p. 100).

\footnotetext{
${ }^{13}$ Art. 51 da Lei 9.610/98: "A cessão dos direitos de autor sobre obras futuras abrangerá, no máximo, o período de cinco anos. Parágrafo único. O prazo será reduzido a cinco anos sempre que indeterminado ou superior, diminuindo-se, na devida proporção, o preço estipulado".

${ }^{14}$ Art. 49, III da Lei 9.610/98: "Os direitos de autor poderão ser total ou parcialmente transferidos a terceiros, por ele ou por seus sucessores, a título universal ou singular, pessoalmente ou por meio de representantes com poderes especiais, por meio de licenciamento, concessão, cessão ou por outros meios admitidos em Direito, obedecidas as seguintes limitações: (...) III - na hipótese de não haver estipulação contratual escrita, o prazo máximo será de cinco anos".
} 
Em suma, entende-se que quando o autor se obriga a não reivindicar a paternidade de determinada obra, autorizando sua publicação anônima ou em nome de outra pessoa, não há que se falar em renúncia ao direito de paternidade, mas sim em não exercício desse direito. A contratação é válida, entretanto, o não exercício do direito de paternidade ficará sempre vinculado a um prazo expressamente previsto no contrato, nunca superior a cinco anos. Findo o prazo estabelecido ou decorrido o prazo de cinco anos, ficará livre o autor para reivindicar a paternidade da obra, não havendo que se falar em pagamento de perdas e danos. Por outro lado, se o autor descumprir o acordado, reivindicando a paternidade antes do término do prazo, mesmo assim deverá ser reconhecido o seu direito de figurar como autor da obra, já que se está diante de direito da personalidade irrenunciável (art. 11 do Código Civil) (ZANINI, 2011, passim), porém, o desrespeito à contratação e à boa-fé conduzirão ao pagamento de perdas e danos. A convenção envolvendo direito de paternidade é, então, revogável ad nutum, podendo o verdadeiro autor, a qualquer momento, pleitear seu direito da personalidade (GAUTIER, 2010, p. 236). Ademais, o reconhecimento da autoria terá eficácia ex nunc, sendo admissível a sua retificação apenas nos suportes produzidos após a decisão judicial $^{15}$. Por fim, o deferimento do pedido de reconhecimento da paternidade da obra não tem o condão de alterar a contratação engendrada no que toca ao direito de utilização da obra, de maneira que o autor terá seu nome ligado ao trabalho por ele criado, mas se cedeu totalmente os direitos de utilização da obra, não será admissível qualquer pretensão pecuniária no que diz respeito aos direitos patrimoniais ${ }^{16}$.

\section{Notas sobre o ghost writer no direito estrangeiro}

\subsection{O ghost writer na Alemanha}

\footnotetext{
${ }^{15}$ Em linhas gerais, a mesma doutrina é defendida por Ascensão: "Este direito pode ser convencionado limitado, como veremos que pode acontecer com todos os direitos pessoais. Assim, o autor compromete-se validamente a não exercer o seu direito em dada relação. Mas não pode renunciar ao direito em si. Nem pode sequer pactuar validamente que um outro será apresentado como autor, pois semelhante contrato violaria a fé pública, por razões análogas às expostas a propósito da exclusão da atribuição originária do direito de autor a outrem. E mesmo o acordo que fizer, de não exercer o seu direito em dada situação, tem mera eficácia obrigacional e não atinge a sua posição de autor. Pode, não obstante, a todo momento reivindicar a paternidade da obra. A sua pretensão, dada a prevalência das razões pessoais, sairá vitoriosa, muito embora fique obrigado à indenização de perdas e danos em benefício daquele com quem contratou" (ASCENSÃO, 2007, p. 142).

${ }^{16}$ Outrossim, é de se observar que o regime jurídico apresentado também se aplica aos casos de obra produzida em falsa colaboração, ou seja, na situação em que duas pessoas aparecem como autores, mas apenas uma delas efetivamente criou o trabalho, o que é muito comum em matéria musical, quando aquele que nada produziu figura como autor ao lado do verdadeiro artista (GAUTIER, 2010, p. 237). 
Na Alemanha os estudiosos também se debruçaram sobre o assunto, apresentando várias teorias para tentar justificar os contratos de ghost writer.

Entre as propostas, podemos citar a de Hansjörg Stolz, que, no livro "Der Ghostwriter im deutschen Recht", admite a validade desses contratos se na obra for expressa a personalidade daquele que não é o seu verdadeiro autor ("Eine vertragliche Gestattung ist zulässig, wenn sich der Ghostwriter bei seinem Schaffen an der Persönlichkeit des Dritten orientiert hat"). Coloca ainda como condicionante a existência de correspondência entre a personalidade daquele que está assumindo a autoria e o estilo e conteúdo do trabalho (STOLZ, 1971, passim).

Todavia, a maioria da doutrina alemã considera que tese de Stolz é muito ampla, abrindo um leque muito extenso e perigoso de exceções à proibição da renúncia ou transferência do direito de paternidade. De fato, os estudiosos alemães têm entendimento convergente no que toca às necessidades práticas relacionadas ao tema, reconhecendo que as convenções que atingem a intransmissibilidade dos direitos da personalidade do autor devem ser tratadas com muita prudência (LUCAS-SCHLOETTER, 2002, p. 459-460).

Ademais, nos casos em que admitem a contratação da manutenção do silêncio do autor quanto ao seu direito de paternidade, ponderam, segundo proposta de Osenberg, que o acordo não poderá superar o prazo de cinco anos. Tal limitação temporal resulta da aplicação por analogia do $\S 41,4$ da UrhG, o qual prevê a impossibilidade de renúncia antecipada do direito de retirada e a proibição de seu não exercício por mais de cinco anos (OSENBERG, 1985, p. $119-120)^{17}$.

Dietz e Peukert não deixam de lembrar as condições apresentadas por Stolz para a admissão de negócios jurídicos envolvendo o direito de paternidade. Aduzem, no entanto, que a renúncia ao referido direito por todo o período de duração dos direitos do autor não pode ser admitida, sendo somente possível que a utilização de um pseudônimo, a publicação anônima da obra, ou em nome de outrem, seja contratualmente exigível pelo período máximo de cinco anos, prazo que deriva da aplicação analógica do § 41, 4 da UrhG (DIETZ; PEUKERT, 2010, p. 240).

O tema é tratado da mesma forma por Rehbinder, o que denota a mencionada unidade do pensamento alemão. Conforme o professor das universidades de Freiburg (Alemanha) e de Zurique (Suíça), apesar de opiniões isoladas admitindo a renúncia, na verdade o direito do

\footnotetext{
${ }^{17} \S$ 41, 4 da UrhG: "Auf das Rückrufsrecht kann im voraus nicht verzichtet werden. Seine Ausübung kann im voraus für mehr als fünf Jahre nicht ausgeschlossen werden". Tradução livre: "O direito de retirada não pode ser antecipadamente renunciado. Seu exercício não pode ser antecipadamente excluído por mais de cinco anos". 
autor ao reconhecimento da autoria é inevitável. A partir daí, elucida que os pactos de ghost writer têm validade, mas seus efeitos dizem respeito apenas ao campo obrigacional, de maneira que um eventual descumprimento conduz simplesmente ao pagamento de indenização por perdas e danos. Ademais, também destaca que os negócios envolvendo o direito de paternidade, por analogia ao disposto no $\S 41,4$ da UrhG, podem ter duração máxima de até cinco anos (REHBINDER, 2010, p. 256).

Por derradeiro, não é diferente o ponto de vista de Schack, o qual destaca que os contratos de ghost writer representam apenas o não exercício obrigacional e limitado no tempo do direito de paternidade. Assim sendo, havendo ou não contratação, é certo que o criador não pode renunciar ao direito de paternidade (SCHACK, 2010, p. 187) ${ }^{18}$.

\section{$7.2 \mathrm{O}$ ghost writer na França}

Na França a doutrina está dividida, sustentando dois pontos de vista diversos. Alguns autores, como Colombet e Sirinelli, pregam simplesmente a nulidade dos contratos de ghost writer, enquanto outros estudiosos, ainda que aguerridos defensores dos direitos da personalidade do autor, são mais comedidos, não reconhecendo a nulidade dos referidos negócios jurídicos (LUCAS-SCHLOETTER, 2002, p. 460).

O segundo posicionamento, advogado por parcela importante dos estudiosos, apesar de se postar a favor do não exercício do direito de paternidade, o que é reputado válido, em contrapartida sujeita tais obrigações à precariedade, de maneira que fica sempre permitido ao autor, a qualquer momento, o direito de se revelar como criador da obra ${ }^{19}$.

$\mathrm{Na}$ jurisprudência francesa há notícia de demandas envolvendo a temática, como ocorre quando se está diante de um coautor que renunciou ao seu direito de paternidade em proveito de seu colaborador (LUCAS-SCHLOETTER, 2002, p. 460-461). Evidentemente,

\footnotetext{
18 A mesma linha de raciocínio é seguida por Schmid, Wirth e Seifert, que esclarecem que os direitos da personalidade do autor não são disponíveis, sendo ineficaz eventual renúncia. Admitem, igualmente, que em uma relação obrigacional não seja exercido, por determinado período, o direito de paternidade (SCHMID; WIRTH; SEIFERT, 2009, p. 90). Wandtke vê o direito ao reconhecimento da autoria como irrenunciável e intransferível, decorrendo tais características do princípio da criação. Assim, este direito não pode ser transferido ao empregador ou a outro colega de trabalho. Destaca, ainda, que o direito de paternidade não pode ser excluído pela lei ou por um contrato, de maneira que quem contratualmente se obriga como ghost writer não está renunciando ao direito de paternidade, mas sim apenas criando um direito de eficácia obrigacional (WANDTKE, 2009, p. 183).

${ }^{19}$ Segundo Pollaud-Dulian, a contratação de "nègre" é precária, pois o verdadeiro autor tem o direito de revelar, a qualquer momento, sua identidade, o que pode ser feito com base no artigo L. 121-1 do Código de Propriedade Intelectual. Destaca ainda que é inconcebível a aplicação na França de uma lei estrangeira que venha a privar o verdadeiro autor de seu direito moral de paternidade (POLLAUD-DULIAN, 2005, p. 389 e 823-824).
} 
isso não é a mesma coisa que a criação integral de uma obra e sua posterior abdicação em favor de terceiro, mas a solução passa pelos mesmos princípios e dispositivos normativos.

Entre os casos que merecem referência, em uma disputa iniciada por Etienne de Montpezat foi discutido o direito de paternidade de uma obra de conteúdo autobiográfico, que foi elaborada por Montpezat em colaboração com as pessoas que são tratadas no livro. A escritora pediu que seu nome constasse nos exemplares da obra, ainda que ela tenha renunciado ao direito de paternidade. A decisão da Corte de Apelação de Paris, em 1986, tomou como válido o acordo de nègre, mas se postou favoravelmente à tese da simples revogabilidade ad nutum do que foi contratado (LUCAS-SCHLOETTER, 2002, p. 462).

Em outro processo, disputou-se a autoria do romance "La nuit du sérail", que tinha sido escrito conjuntamente por Michel de Grèce e Anne Bragance. A despeito da colaboração dos dois autores para a criação da obra, Bragance renunciou à autoria em favor de Grèce, de maneira que a obra foi publicada apenas no nome do último. O caso envolvia a possibilidade de renúncia ao direito de paternidade, a validade do contrato de nègre, bem como a definitividade ou não da renúncia. A conclusão da Corte de Apelação de Paris foi no sentido de admitir a validade da cláusula que estabelecia a renúncia da autoria de um criador em benefício de outro, porém, ao mesmo tempo, permitiu a Bragance o afastamento ex nunc da cláusula abdicativa, autorizando a inclusão de seu nome nos exemplares futuros da obra (LUCAS-SCHLOETTER, 2002, p. 462).

No mesmo sentido, poder-se-ia citar outros casos, no entanto, já restou claro que a jurisprudência francesa mais recente tem reconhecido, majoritariamente, a validade dos contratos de nègre. Em contrapartida, autoriza que o acordo entabulado seja revogado ad nutum, cujos efeitos serão sentidos somente a partir do momento em que o negócio jurídico foi denunciado (LUCAS-SCHLOETTER, 2002, p. 464). E essa mesma lógica, conforme ensina Gautier, também deve ser aplicada às oficinas de escrita (ateliers d'écriture), que se utilizam do trabalho anônimo de vários autores para redigir textos para uma equipe de autores identificados, situação que deve ser tratada com todo rigor pelos juízes, para que se coíbam novas formas de servidões pessoais (GAUTIER, 2010, p. 236).

\section{Considerações finais}

Diante dos estudos apresentados, é certo que as decisões judiciais do caso Bruna Surfistinha se pautaram pela inexistência da produção de uma obra intelectual por parte do 
escritor. Esse foi o caminho mais simplista para a resolução da disputa judicial, ou seja, considerou-se que o escritor não produziu uma obra passível de proteção, pois os julgados entenderam que a obra foi produzida pela protagonista Raquel.

A despeito das decisões judiciais, foi demonstrado no presente trabalho que o escritor da obra realmente produziu um trabalho digno de proteção pelo direito de autor, o que afasta integralmente a fundamentação exposta nos julgados. Aliás, se for traçado um paralelo com notícias jornalísticas, nelas os acontecimentos não são criados pelo jornalista, mas se protege a criação jornalística pelo fato do jornalista ter criado um texto relatando os fatos. E isso não é muito diferente do ocorrido no caso Bruna Surfistinha. Desse modo, deve-se admitir a existência de uma obra protegida produzida pelo escritor, o que transfere o problema para a questão da contratação de um escritor-fantasma.

Pois bem, ao ghost writer faz-se mister o reconhecimento dos direitos de paternidade e de reivindicação da autoria da obra, o que assegura a proteção ao verdadeiro criador intelectual. Nessa senda, quando o verdadeiro autor se obriga a não reivindicar a paternidade de determinada obra, autorizando sua publicação anônima ou em nome de outra pessoa, não há que se falar em renúncia ao direito de paternidade, mas sim em não exercício desse direito. A contratação é válida, entretanto, o não exercício do direito de paternidade ficará sempre vinculado a um prazo expressamente previsto no contrato, não superior a cinco anos. Findo o prazo estabelecido, ou decorrido o prazo de cinco anos, ficará livre o verdadeiro autor para reivindicar a paternidade da obra, não havendo que se falar em pagamento de perdas e danos.

Por outro lado, se o autor descumprir o acordado, reivindicando a paternidade antes do término do prazo, mesmo assim deverá ser reconhecido o seu direito de figurar como autor da obra, já que se está diante de direito da personalidade irrenunciável (art. 11 do Código Civil). Todavia, o desrespeito à contratação poderá levar ao pagamento de perdas e danos.

Nesse contexto, fica evidente que a convenção envolvendo o direito de paternidade é revogável ad nutum, podendo o verdadeiro autor, a qualquer momento, pleitear seu direito da personalidade. Ademais, o reconhecimento da autoria terá eficácia ex nunc, sendo admissível a sua retificação apenas nos suportes produzidos após a decisão judicial, solução que se apresenta como a mais razoável para todos os envolvidos na contratação.

Outrossim, o deferimento do pedido de reconhecimento da paternidade da obra não tem o condão de alterar a contratação engendrada no que toca ao direito de utilização da obra, de maneira que o autor terá seu nome ligado ao trabalho por ele criado, mas se cedeu os 
direitos de utilização da obra, eventual pretensão pecuniária será regida pelas disposições estabelecidas na contratação realizada.

Por conseguinte, não resta dúvida que as proposições apresentadas divergem, em grande medida, dos julgados proferidos pelo Poder Judiciário, pois se permite ao escritorfantasma a possibilidade de reivindicar, a qualquer momento, a autoria da obra produzida, o que está em consonância com os direitos da personalidade do autor, que constituem o núcleo fundamental da proteção autoral. E para além da tutela dos direitos da personalidade do autor, a solução aqui apresentada também é dotada de caráter pedagógico, visto que inibe a contratação de escritores-fantasmas, na medida em que sobre o contratante sempre pairará dúvida acerca da possibilidade de reivindicação a qualquer momento da autoria, o que pode colaborar para a redução da prática da contratação de ghost writer, bem como até promover a sua consequente extinção no longo prazo.

\section{Referências}

ASCENSÃO, José de Oliveira. Direito autoral. 2. ed. Rio de Janeiro: Renovar, 2007.

BRASIL. Superior Tribunal de Justiça. Recurso Especial nº 1387242 2012.01.62477-2.

Relator: Min. Paulo de Tarso Sanseverino. Brasília, 19 fev. 2015. Disponível em: $<$ https://scon.stj.jus.br/SCON/jurisprudencia/toc.jsp?processo=1387242\&b=ACOR\&thesauru $\mathrm{s}=$ JURIDICO\&p=true $>$. Acesso em: $9 \mathrm{dez} .2019$.

BRASIL. Tribunal de Justiça de Minas Gerais. AC: 10570110000033002. Relator: Luiz Carlos Gomes da Mata. Belo Horizonte, 2 fev. 2016. Disponível: em:

<https://www4.tjmg.jus.br/juridico/sf/proc_resultado2.jsp?tipoPesquisa2 $=1 \&$ txtProcesso=105 $70110000033002 \&$ nomePessoa $=\&$ tipoPessoa $=X \&$ naturezaProcesso $=0 \&$ situacaoParte $=X \& c 0$ digoOAB2 $=\&$ tipoOAB $=\mathrm{N} \&$ ufOAB $=$ MG\&numero $=20 \&$ select $=1 \&$ listaProcessos $=105701100$ $00033002 \&$ tipoConsulta $=1 \&$ natureza $=0 \&$ ativoBaixado $=X \&$ comrCodigo $=0024>$. Acesso em: 9 dez. 2019.

BRASIL. Tribunal de Justiça de São Paulo. Apelação nº 0181194-46.2008. Relator: Des. Coelho Mendes. São Paulo, 5 abr. 2011. Disponível em:

<https://esaj.tjsp.jus.br/cjsg/getArquivo.do?cdAcordao=5075844> . Acesso em: 9 mar. 2019.

CHINELLATO, Silmara Juny de Abreu. Direito de autor e direitos da personalidade: reflexões à luz do Código Civil. Tese para Concurso de Professor Titular de Direito Civil da Faculdade de Direito da Universidade de São Paulo. São Paulo: Universidade de São Paulo, 2008.

CUPIS, Adriano de. Os direitos da personalidade. Trad. Afonso Celso Furtado Rezende. Campinas: Romana, 2004. 
DIETZ, Adolf; PEUKERT, Alexander. $§ 15, \S 16$ A, B, E und F, § 17. In: LOEWENHEIM, Ulrich (Hrsg.). Handbuch des Urheberrechts. 2. ed. München: C. H. Beck, 2010, p. 236-255.

DIETZ, Adolf; PEUKERT, Alexander. Vor $\S \S 12$ ff., $\S ~ 12-14,42$. In: SCHRICKER,

Gerhard; LOEWENHEIM, Ulrich (Hrsg.). Urheberrecht: Kommentar. 4. ed. München: C. H. Beck, 2010, 862-874

DIETZ, Claire. Rechte des Urheber: Urheberpersönlichkeitsrecht. In: WANDTKE, ArturAxel (Hrsg.). Urheberrecht. Berlin: De Gruyter, 2009, p. 90-105.

GAUTIER, Pierre-Yves. Propriété littéraire et artistique. 7. ed. Paris: PUF, 2010.

LETTL, Tobias. Urheberrecht. München: C.H.Beck, 2008.

LIPSZYC, Delia. Derecho de autor y derechos conexos. Buenos Aires: UNESCO, 1993.

LUCAS, André; LUCAS, Henri-Jacques. Traité de la propriété littéraire et artistique. 3. ed. Paris: Litec, 2006.

LUCAS-SCHLOETTER, Agnès. Droit moral et droits de la personnalité: étude de droit compare français et allemand. Aix-en-provence: PUAM, 2002.

MORAES, Walter. Questões de Direito de Autor. São Paulo: Revista dos Tribunais, 1977.

OSENBERG, Ralph. Die Unverzichtbarkeit des Urheberpersönlichkeitsrechts. Freiburg: Hochschulverlag, 1985.

POLLAUD-DULIAN, Frédéric. Le droit d'auteur. Paris: Economica, 2005.

PONTES DE MIRANDA, Francisco Cavalcanti. Tratado de direito privado. Campinas: Bookseller, 2000, t. VII.

REHBINDER, Manfred. Urheberrecht. 16. ed. München: C. H. Beck, 2010.

SCHACK, Haimo. Urheber- und Urhebervertragsrecht. 5. ed. Tübingen: Mohr Siebeck, 2010.

SCHMID, Matthias; WIRTH, Thomas; SEIFERT, Fedor. Urheberrechtsgesetz mit Urheberrechtswahrnehmungsgesetz: Handkommentar. 2. ed. Baden-Baden: Nomos, 2009.

STOLZ, Hansjörg. Der Ghostwriter im deutschen Recht. München: C.H. Beck, 1971.

STROWEL, Alain. Droit d'auteur et copyright: divergences et convergences. Paris: LGDJ, 1993.

VIVANT, Michel; BRUGUIÈRE, Jean-Michel. Droit d'auteur. Paris: Dalloz, 2009.

WANDTKE, Artur-Axel. Urhebervertragsrecht. In: WANDTKE, Artur-Axel (Hrsg.). Urheberrecht. Berlin: De Gruyter, 2009, p. 133-185. 
ZANINI, Leonardo Estevam de Assis. Direito Civil: Direito das Coisas. Rio de Janeiro: Lumen Juris, 2019.

. Direito de autor. São Paulo: Saraiva, 2015.

Direitos da personalidade. São Paulo: Saraiva, 2011.

Data de recebimento: 03.07.2020

Data de aprovação: 28.08.2020 